\title{
Interactive comment on "A 2D model for simulating heterogeneous mass and energy fluxes through melting snowpacks" by N. R. Leroux and J. W. Pomeroy
}

N. R. Leroux and J. W. Pomeroy

nicolas.leroux@usask.ca

Received and published: 18 June 2016

The comment was uploaded in the form of a supplement:

http://www.the-cryosphere-discuss.net/tc-2016-55/tc-2016-55-AC4-supplement.pdf

Interactive comment on The Cryosphere Discuss., doi:10.5194/tc-2016-55, 2016. 